some species and their change in form as being the major reason for their belief. Rock or fossil evidence, or the study of skeletons and remains was mentioned much less often.

Of those who disbelieved in the theory, about half gave their belief in God as the prime reason. Other reasons put forward by very small minorities of the total sample were "because believing in the religious view is the best thing", "because I am a Roman Catholic", or "because I just don't believe it".
Asked what would ultimately happen to man, almost half the viewers were not prepared to volunteer any answer. The replies of those who did were diffuse. In descending order of frequency the forecasts were : (1) that man would suffer destruction at his own hands; (2) that he would increase his power and conquer space; (3) that there would be development of brain power, or that man would lose certain parts, such as his toes. A few thought man to be "at his peak" and not likely to change further.

\title{
CHEMICALS DISSOLVED IN RAIN WATER
}

$\mathrm{T}$ HE study of the nature of the chemicals dissolved in rain water is important to the agriculturalist and botanist because of their effect in the nutrition of plants and to the meteorologist for the light thrown on the physics of rain formation and on atmospherie diffusion.

Much work has been done on this matter in Sweden in recent years. There it has been found that very near the coast the predominant elements are sodium and chlorine in nearly the same ratio as in sea water (sodium/chloride ratio 0.85 ) but that inland the proportion of sodium increases rapidly. No satisfactory reason for this increase inland has been put forward.

Mr. E. Gorham, of the Freshwater Biological Association, Ambleside, Westmorland, has recently published* similar analyses of precipitation falling at a point on Hawkshead Moor during January 1955January 1956.

$\mathrm{He}$ found a close correlation between the amounts of sodium and chlorine, with a ratio of sodium to chloride almost the same as that in sea water, and also a close connexion between the amounts of hydrogen, potassium, calcium, nitrate and sulphate ions. There was a remarkably clear association between the chemical constitution of the solutes and wind direction. Rain falling with south-westerly winds contained much more chloride than that with winds from other directions, and similarly, rain with southeasterly winds contained much higher amounts of sulphate and nitrate. The latter effect is naturally attributed to atmospheric pollution from the industrial areas to the south-east of the site. Comparison of

* Philosophical Transactions of the Royal Society of Lomdon. Series B : Biological Sciences. No. 679, Vol. 241 (9 January, 1958): The Infiuence and Importance of Daily Weather Conditions in the Supply of Chloride, Sulphate and other Ions to Fresh Waters from Atmospheric Precipitation. By E. Gorham. Pp. 147-178. (London: Roya) Society, 1958.) 108 . hydrogen-ion concentration and sulphate plus nitrate concentration shows that hydrogen and sulphate are largely combined as sulphuric acid. The ratio of sodium to chloride did not, however, vary with wind direction in the way that would have been expected from the Swedish observations. The amounts of both chloride and sulphate plus nitrate increased with wind speed, the observed variation being a tenfold increase for the first and two-fold for the second. This supports the sea-spray theory of the principal source of atmospheric chloride and agrees with observations at Hawaii.

A further result is that rain, in which the ratio of sodium to chloride was less than 0.8 , fell predominantly with easterly winds containing a high proportion of sulphate. This suggested that some chloride is supplied by atmospheric pollution, and a study of the chloride in smoke solids collected by filters in London buildings is found to support this theory. The opposite phenomenon of excess sodium values, the criterion being a sodium chloride ratio of 0.95 , occurred in small showers, the highest value of excess sodium occurring in a hail shower. It was first thought that the excess sodium might be produced in these showers by local rock dust, but analysis of lake waters which might equally be expected to show the same effect did not support the hypothesis. Taking the hint from the hail shower, the author then carried out an experiment to see if chemical reaction between sulphuric acid and sodium chloride leading to production of gaseous hydrochloric acid were facilitated by freezing. This was found to be the case, and he suggests that it is possible that excess sodium occurs because the increase in concentration of the solutes brought about by freezing leads to production and subsequent escape of hydrochloric acid.

\section{OXIDATIVE PHOSPHORYLATION : A CHEMICAL APPROACH USING QUINOL PHOSPHATES}

\author{
By DR. V. M. CLARK, G. W. KIRBY and SIR ALEXANDER TODD, F.R.S. \\ University Chemical Laboratory, Cambridge
}

$\mathrm{T}$ THE ubiquitous occurrence of phosphate and polyphosphate esters in biological systems has, in recent years, stimulated widespread interest in problems of chemical phosphorylation'. For the solution of such problems, the phosphorus atom of the phosphorylating agent must be the centre for nucleophilic attack ${ }^{2}$ and with the common reagents, for example, the phosphorochloridates ${ }^{3}$ and pyrophosphates $^{4}$, acylation proceeds with the expulsion of an anion (reactions $1,2,3$ ).

The phosphoramidates, another type of reagent, require to be in the zwitterionic form to exhibit their acylating function, the expelled group then being a neutral amine molecule (reaction 4). 